\title{
Gastrointestinal poliplerin boyut, lokalizasyon ve histopatolojk tipleriyle değerlendirilmesi
}

Evaluation of gastrointestinal polyps according to their size, localization and histopathologic types

Yasemin DÖLEK ${ }^{1}$, Yasemin YUYUCU KARABULUT ${ }^{1}$, Firdevs TOPAL ${ }^{2}$, Nazmiye KURŞUN $^{3}$

Çankırı Devlet Hastanesi, ${ }^{1}$ Patoloji Bölümü, ${ }^{2}$ Gastroentroloji Bölümü, Çankın

Ankara Üniversitesi Tip Fakültesi, ${ }^{3}$ Biyoistatistik Anabilim Dall, Ankara

Amaç: Çalıs̆madaki amacımız merkezimizde tanı alan üst ve alt gastrointestinal sisteme ait polipektomi materyallerinin histopatolojik tipleri ile birlikte dökümante edilmesidir. Gereç ve Yöntem: Çalısmada Çankırı Devlet Hastanesi Patoloji Laboratuvarnnda 2011 - 2012 yilları arasında histopatolojik tan verilen 271 adet gastrointestinal polip olgusu retrospektif olarak incelendi. Yerleşim özellikleri ve histopatolojik tiplerine göre polipler kaydedildi. Bulgular: Hastaların \%69,4’ü erkek, \%30,6’sı kadındı. Yaș dağılımı 2-91 yıl arasinda değişmekte olup, yaş ortalaması $61,7 \mathrm{yll}$, ortalama boyut $8 \mathrm{~mm}$ olarak saptandı. Gastrointestinal sistem polipleri yerleşim bölgeleri açısından değerlendirildiğinde 271 olgunun 233'ü kolon, 38'i mide yerleşimliydi. Kolon yerleşimli poliplerin büyük kısmının rektumda (\%36,2), mide yerleşimli poliplerin ise büyük kısmının antrumda $(\% 6,3)$ oldukları saptandı. Gastrointestinal sistem poliplerinde histopatolojik tipler açısından en büyük hasta grubunu $161(\% 59,4)$ olgu ile tübüler adenom oluștururken, bunu $63(\% 23,2)$ olgu ile hiperplastik polipler takip etmekteydi. Kolondaki polipler erkeklerde daha sık görülürken, mide lokalizasyonlu polipler kadınlarda daha sık saptandı. Tartışma: Üst ve alt gastrointestinal sisteme ait polipleri ayrı ayrı değerlendirdiğimiz çalışmamızda genel olarak tüm sonuçlarımızın literatür ile uyumluluk halinde olduğu görüldü.

Anahtar Kelimeler: Gastrointestinal polipler, histopatolojik tip, lokalizasyon

\section{GİRISş}

Gastrointestinal polipler mukoza ve submukoza epitelinden köken alan ve mide barsak lümeni içine doğru çıkıntı yaparak kitle oluşturan proliferatif ve neoplastik lezyonlardır. Gastrointestinal sistem (GIS) polipleri daha sik olarak kolorektal bölgede görülürler. Kolonoskopik inceleme sonucu saptanan polipler saplı, sapsız olabilirler, büyüklükleri değişkendir (1). Kolorektal polipler non-neoplastik polipler [hiperplastik (metaplastik) polipler, hamartomatöz polipler (jüvenil polipozis, peutz jegher sendromu, Cronkhite-Canada sendromu, Cowden sendromu), inflamatuvar polipler], neoplastik polipler adenomlar (tübüler, tübülovillöz, villöz) olarak sınıflandırılmaktadır (2,3). Mide poliplerine üst GIS endoskopik incelemelerinde \%2-3 oranında rastlanır $(4,5)$. Mide polipoid lezyonları güncel ve yaygın kabul gören modifiye Dünya Sağlık Örgütü (WHO) sinıflandırılmasında non-neoplastik polipoid lezyonlar (hiperplastik polipler, fundik gland polipleri, inflamatuvar fibroid polip, hamartomatöz polipler, heterotopik doku polipleri), neoplastik polipoid lezyonlar [epitelyal be-
Background and Aims: We aimed to document upper and lower gastrointestinal system polyps in our center according to their types. Materials and Methods: 271 gastrointestinal polyps that were histopathologically diagnosed at Çankır State Hospital during the period 2011-2012 were included in the study. Polyps were noted according to their localization and histopathologic types. Results: $69.4 \%$ of the patients were males and $30.6 \%$ were females, and their mean age was 61.7 years. The mean diameter of the polyps was 8 $\mathrm{mm} .233$ of the polyps were located in the colon and the remainder in the stomach. Colonic polyps were most commonly seen in the rectum (36.2\%), while gastric polyps were most commonly seen in the antrum (6.3\%). Colonic polyps were most common in males, while gastric polyps were most common in females. Conclusions: In this study, in which we evaluated upper and lower gastrointestinal polyps separately, our results were found to be similar to those reported in the literature.

Keywords: Gastrointestinal polyps, histologic types, localization

nign tümörler (tübüler adenom, tübülovillöz adenom, villöz adenom, pylorik gland adenomu), epitelyal malign tümör, endokrin tümörler, mezenkimal benign tümörler, mezenkimal malign tümörler, lenfoid tümör] ve reaktif polipoid lezyonlar (foveolar hiperplazi, lenfoid folliküller, gastritis varioliformis, gastritis kistika profunda) olarak sinıflandırılmaktadır (4).

Adenomlar hafif, orta ve şiddetli displazi içerebilir. Tübüler adenomlar genellikle küçüktür ve hafif derecede displazi gösterirler. Polip çapı büyüdükçe ve villöz olanlarda displazi artmaktadır. Tübüler adenomlarda \%88 hafif, \%8 orta, \%4 şiddetli displazi; tübülovillöz adenomlarda \%58 hafif, \%26 orta, \%16 şiddetli displazi; villöz adenomlarda \%41 hafif, \%38 orta, \%21 şiddetli displazi görülmektedir $(2,3)$.

Inflamatuvar polipler kronik inflamasyona yanıt olarak gelişen, iltihabi barsak hastalıkları gibi durumlarda görülen poliplerdir. Çoğu rektumda görülür, çapları 2-3 cm arasında değişmektedir. 
Hiperplastik polipler en sık görülen nonneoplastik poliplerdir. Karakteristik olarak sesil, 5 mm'den küçük lezyonlardır. Büyük polipler saplı olabilir. Özellikle distal kolon ve rektumda görülür $(1,3)$.

Çalışmadaki amacımız merkezimizde tanı alan üst ve alt gastrointestinal sisteme ait polipektomi materyallerinin tipleri ile birlikte dökümante edilmesidir.

\section{GEREC VE YÖNTEM}

Çalışmada Çankırı Devlet Hastanesi Patoloji Laboratuvarında 2011- 2012 yılları arasında histopatolojik tanı verilen 271 adet gastrointestinal polip olgusu retrospektif olarak incelendi. Yerleşim özellikleri: rektum, sigmoid kolon, inen kolon, transvers kolon, çekum, çıkan kolon, mide fundus, mide korpus ve mide antrum olmak üzere 9 bölgeye ayrlarak kaydedildi. Olguların hematoksilen-eozin ile boyanmıs kesitleri yeniden gözden geçirildi ve histopatolojik tanılar tübüler adenom (Resim 1-A, B), tübülovillöz adenom (Resim 2), hiperplastik polip (Resim 3-A, B), inflamatuvar polip (Resim 4), yüzeyel kanserleşme gösteren tübüler adenom, yüzeyel kanserleşme gösteren tübülovillöz adenom, kanserleşme gösteren tübüler adenom ve fundik gland polibi olmak üzere 8 gruba ayrilarak kaydedildi. Hastalara ait demografik verilere hastane bilgi sisteminden ulaşıldı. Çalışma Helsinki Deklerasyonu 2008 prensiplerine uygun olarak yürütüldü. Istatistiksel değerlendirmede SPSS 15 Word paketi kullanıldı.
Değişkenlerin karşılaştırılmasında Ki kare ve Mann Whitney testleri kullanıldı. $\mathrm{P}<0.05$ değeri istatistiksel olarak anlamlı kabul edildi.

\section{BULGULAR}

Çalışmaya gastrointestinal bölgede polip tanısı alan toplam 271 hasta dahil edildi. Hastaların 188'i $(\% 69,4)$ erkek, 83'ü $(\% 30,6)$ kadındı. Yaş dağılımı 2-91 yıl arasında değişmekte olup, yaş ortalaması 61,7 yıl, ortalama boyut $8 \mathrm{~mm}$ (2-70 mm) olarak saptandı. GIS polipleri yerleşim bölgeleri açısından değerlendirildiğinde 271 olgunun 233'ü kolonda, 38'i midede yerleşimliydi. Kolonda lokalize poliplerin 98' i $(\% 36,2)$ rektumda, 45’i $(\% 16,6)$ transvers kolonda, 10'u $(\% 3,7)$ çıkan kolonda, 36'sı $(\% 13,3)$ inen kolonda, 16'sı $(\% 5,9)$ çekumda, 28'i $(\% 10,3)$ sigmoid kolonda izlendi. Midede lokalize poliplerin ise 17'si $(\% 6,3)$ antrumda, 13'ü $(\% 4,8)$ korpusda, 8'i (\%3) fundusda yerleşim göstermekteydi. GiS poliplerde histopatolojik tipler açısından en büyük hasta grubunu 161 $(\% 59,4)$ olgu ile tübüler adenom oluştururken, bunu sıklık sirasına göre $63(\% 23,2)$ olgu ile hiperplastik polip, $22(\% 8,1)$ olgu ile tübülovillöz adenom, 17 (\%6,3) olgu ile inflamatuvar polip, $3(\% 1,1)$ olgu ile yüzeyel kanserleşme göteren tübülovillöz adenom, $2(0,7)$ olgu ile yüzeyel kanserleşme gösteren adenomatöz polip, $2(\% 0,7)$ olgu ile fundik gland polibi ve $1(\% 0,4)$ olgu ile kanserleşme gösteren tübüler adenom takip etmekteydi. GIS polipleri tip ve lokalizasyon açısından

\section{Tablo 1: Poliplerin lokalizasyonuna göre tiplerin değerlendirilmesi}

\begin{tabular}{|c|c|c|c|c|c|c|c|c|c|c|c|c|c|c|c|c|}
\hline \multirow[t]{2}{*}{ Lokalizasyon } & \multicolumn{2}{|c|}{$\begin{array}{l}\text { Tübüler } \\
\text { adenom }\end{array}$} & \multicolumn{2}{|c|}{$\begin{array}{l}\text { Tübülovillöz } \\
\text { adenom }\end{array}$} & \multicolumn{2}{|c|}{$\begin{array}{l}\text { Hiperplastik } \\
\text { polip }\end{array}$} & \multicolumn{2}{|c|}{$\begin{array}{l}\text { Inflamatuvar } \\
\text { polip }\end{array}$} & \multicolumn{2}{|c|}{$\begin{array}{l}\text { Yüz. Kanser. } \\
\text { Tüb. Adenom }\end{array}$} & \multicolumn{2}{|c|}{$\begin{array}{l}\text { Yüz.Kanser. } \\
\text { tübülovillö̈z } \\
\text { adenom }\end{array}$} & \multicolumn{2}{|c|}{$\begin{array}{l}\text { Fundik gland } \\
\text { polip }\end{array}$} & \multicolumn{2}{|c|}{$\begin{array}{l}\text { Kanser. Tüb. } \\
\text { Adenom }\end{array}$} \\
\hline & $\mathrm{N}$ & $\%$ & $\mathrm{~N}$ & $\%$ & $\mathrm{~N}$ & $\%$ & $\mathrm{~N}$ & $\%$ & $\mathrm{~N}$ & $\%$ & & & $\mathrm{~N}$ & $\%$ & $\mathrm{~N}$ & $\%$ \\
\hline Rektum & 51 & 52 & 9 & 9,2 & 18 & 18,4 & 14 & 14,3 & 2 & 2 & 3 & 3,1 & 0 & 0 & 1 & 1 \\
\hline Sigmoid kolon & 19 & 67,9 & 6 & 21,4 & 3 & 10,7 & 0 & 0 & 0 & 0 & 0 & 0 & 0 & 0 & 0 & 0 \\
\hline Inen kolon & 30 & 83,3 & 2 & 5,6 & 2 & 5,6 & 2 & 5,6 & 0 & 0 & 0 & 0 & 0 & 0 & 0 & 0 \\
\hline Transvers kolon & 40 & 88,9 & 2 & 4,4 & 2 & 4,4 & 1 & 2,2 & 0 & 0 & 0 & 0 & 0 & 0 & 0 & 0 \\
\hline Çekum & 14 & 87,5 & 1 & 6,2 & 1 & 6,2 & 0 & 0 & 0 & 0 & 0 & 0 & 0 & 0 & 0 & 0 \\
\hline Çıkan kolon & 7 & 70 & 2 & 20 & 1 & 10 & 0 & 0 & 0 & 0 & 0 & 0 & 0 & 0 & 0 & 0 \\
\hline Mide & 0 & 0 & 0 & 0 & 36 & 94,7 & 0 & 0 & 0 & 0 & 0 & 0 & 2 & 5,3 & 0 & 0 \\
\hline
\end{tabular}

\section{Tablo 2: Polip lokalizasyonu, cinsiyet ve boyut değerlendirilmesi}

Lokalizasyon

\begin{tabular}{lcl}
\hline Lokalizasyon & \multicolumn{2}{c}{ Erkek } \\
\hline Rektum & N \\
\hline Sigmoid kolon & 70 \\
\hline Inen kolon & 20 \\
\hline Trans. kolon & 25 \\
\hline Çekum & 39 \\
\hline Çikan kolon & 9 \\
\hline Mide & 9 \\
\hline
\end{tabular}

Cinsiyet

$\%$

71,4

71,4

69,4

86,7

56,2

90

42,1
Kadın

Boyut (mm)

$\begin{array}{ll} & \text { Kadin } \\ \mathbf{N} \\ 28 \\ 8 \\ 11 \\ 6 \\ 7 \\ 1 \\ 22\end{array}$

$\%$
28,6
28,6
30,6
13,3
43,8
10
57,9

Min. Mak. Ortalama

$\begin{array}{lll}3 & 40 & 8.5 \\ 4 & 20 & 8.7 \\ 3 & 15 & 6.6 \\ 4 & 70 & 7.5 \\ 3 & 25 & 6.9 \\ 3 & 25 & 8.5 \\ 2 & 25 & 8.2\end{array}$




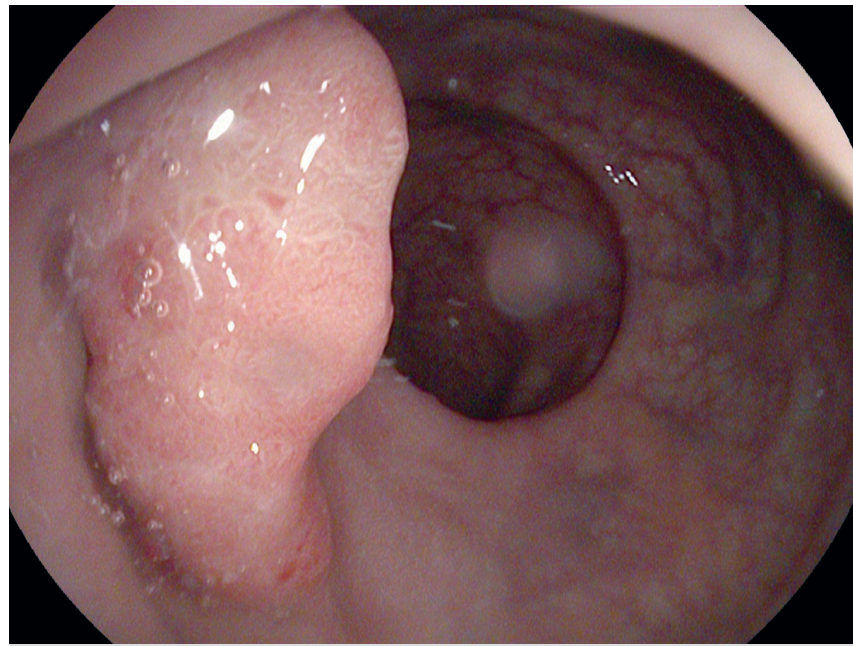

Resim 1-A. Transvers kolon yerleşimli polip.

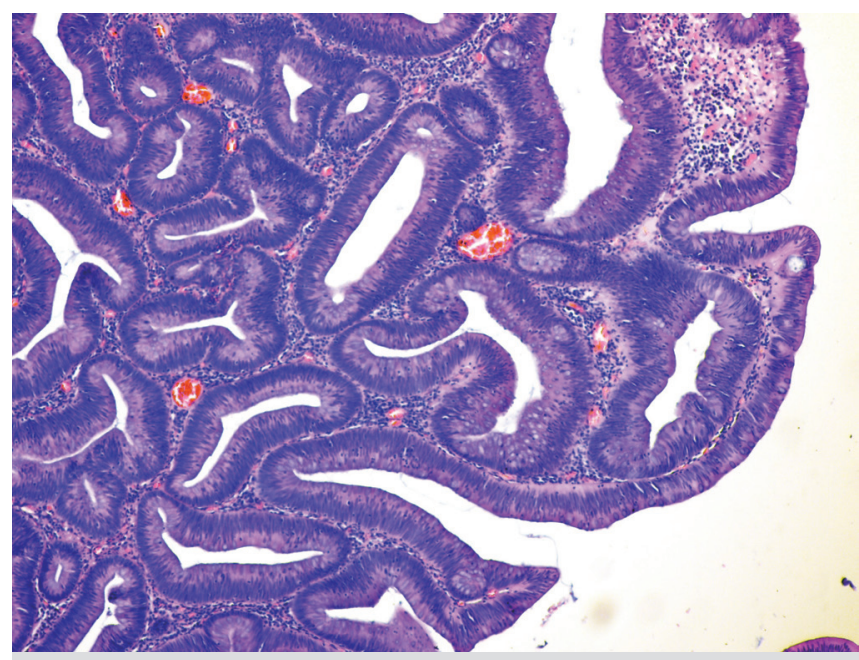

Resim 1-B. Polibin histopatolojik görüntüsü, adenomatöz epitelle döşeli kriptler. H\&Ex100.

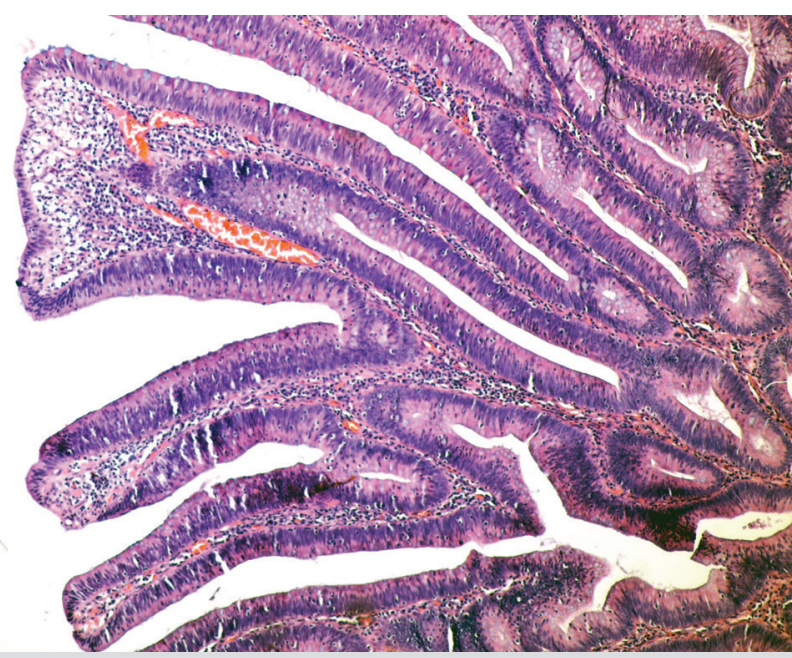

Resim 2. Adenomatöz polip- villöz adenom, adenomatöz epitelle döşeli villuslar. $H \&$ Ex100

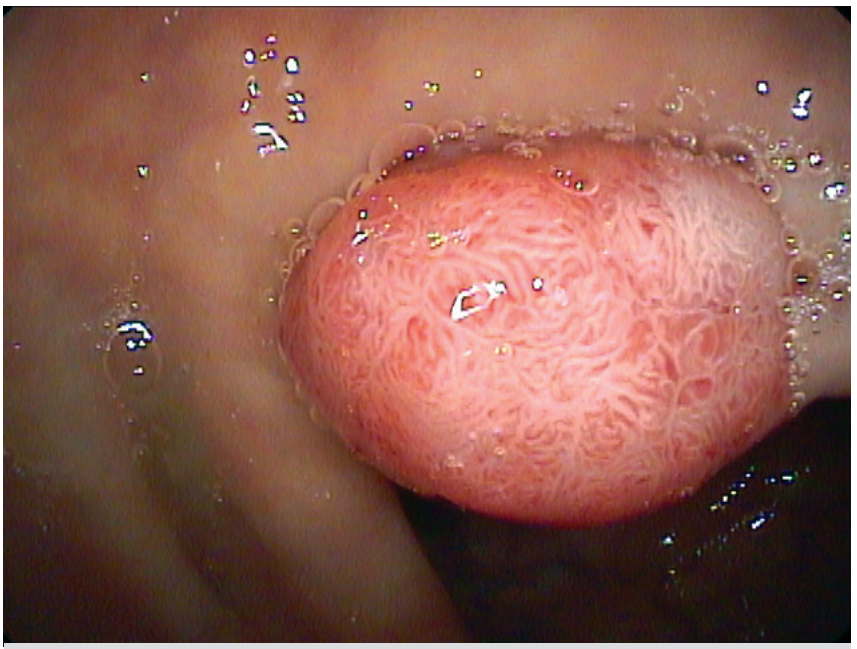

Resim 3-A. Mide yerleşimli hiperplastik polip.

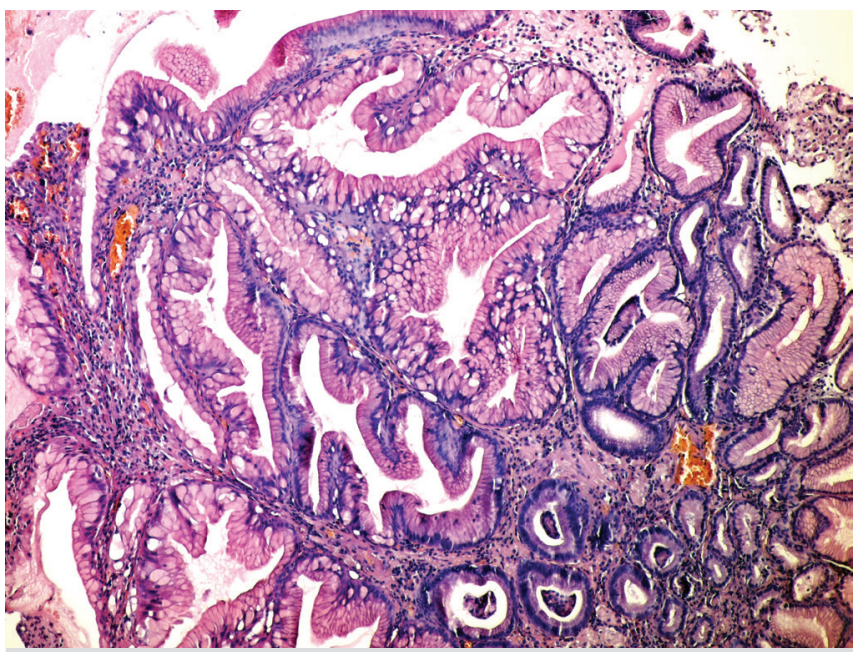

Resim 3-B. Polibin histopatolojik görüntüsü, hiperplastik kriptler. H\&Ex200

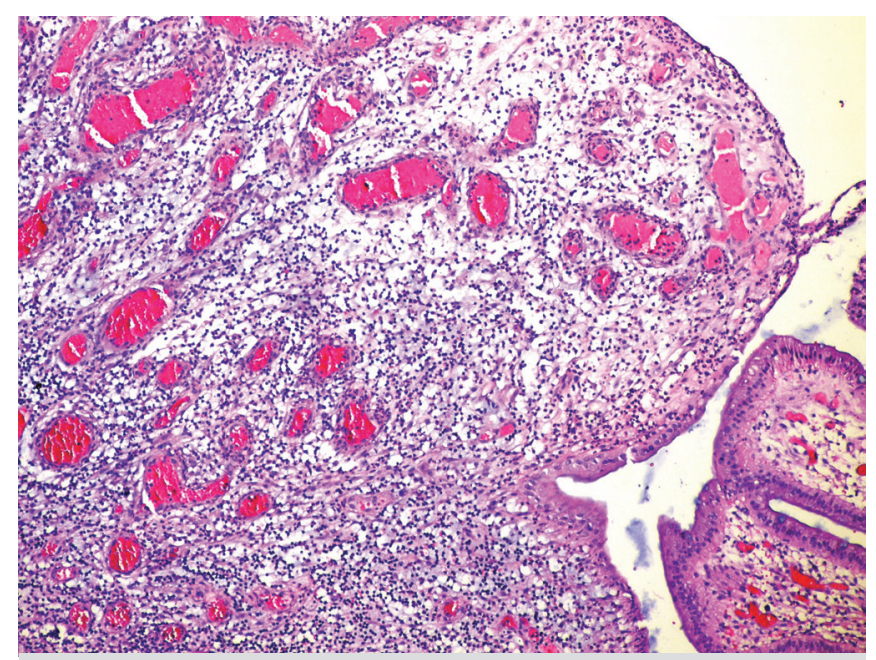

Resim 4. Inflamatuvar zeminde dilate vasküler yapıları ile inflamatuvar polip. H\&Ex200 
değerlendirildiğinde rektum lokalizasyonunda en sik (\%52) tübüler adenom, ikinci sıklıkta $(\% 18,4)$ hiperplastik polip; sigmoid kolonda \%67,9 tübüler adenom, \%21,4 tübülovillöz adenom, \%10,7 hiperplastik polip; inen kolonda \%83,3 tübüler adenom, \%5,6 tübülovillöz adenom ve hiperplastik polip; transvers kolonda \%88,9 tübüler adenom, \%4,4 tübülovillöz adenom ve hiperplastik polip; çekumda $\% 87,5$ tübüler adenom, \%6,2 tübülovillöz adenom ve hiperplastik polip; çıkan kolonda \%70 tübüler adenom, \%20 tübülovillöz adenom, \%10 hiperplastik polip; mide fundus, korpus ve antrumda \%94,7 hiperplastik polip, \%5,3 fundik gland polip saptandı (Tablo 1). Kolondaki polipler erkeklerde daha sık görülürken, mide lokalizasyonlu polipler kadınlarda daha sık saptandı. Lokalizasyona göre polip boyutları arasında fark izlenmedi. Rektum, sigmoid kolon, çıkan kolon ve midede görülen poliplerin boyut ortalaması yaklaşık $8 \mathrm{~mm}$ iken, transvers kolonda $7,5 \mathrm{~mm}$, çekumda 6,9 $\mathrm{mm}$, inen kolonda 6,6 mm olarak saptandı (Tablo 2).

\section{TARTIŞMA}

En sık görülen benign mide tümörleri poliplerdir. Genellikle asemptomatik olan mide polipleri 5-6. dekatlarda daha sik görülürler. Çalışmamızda mide polibi izlenen hastaların yaş ortalaması 63,3 yıl olarak bulundu ve kadınlarda $\% 57,9$ oranı ile bir miktar daha sık izlendikleri görüldü.

Hiperplastik polipler mide poliplerinin \%75-90'ını oluştururlar. Nonneoplastik nitelikteki bu polipler, yaşlılarda sıktır, 6. ve 7. dekadlarda pik yaparlar. Cinsiyete göre görülme sıklıkları değişmez (6-8). Genellikle 1,5 santimetreden küçük, tek, sesil lezyonlar şeklinde olup, sıklıkla korpus-antrum bileşkesinde ortaya çıkarlar ve \%20 oranında multipl olabilirler. Malignite gelişimiyle ilişkileri incelendiğinde bunların daha ziyade maligniteye eşlik eden lezyonlar olduğu, malign dönüşümün nadir olduğu ve bunun daha çok atrofik gastritle ilgili olduğu bulunmuştur (10-13). Bizim çalışmamızda midede \%94,7 oranında hiperplastik polip saptandı. Hiperplastik poliplerin 17'si mide antrumda, 13'ü mide korpusda, 6'sı mide fundusda yerleşim göstermekteydi. Fundik gland polipleri normal mide mukozasında gelişirler ve uzun süreli proton pompa inhibitörü tedavisi uygulanan hastalarda sık görüldüğü bildirilmektedir $(4,9)$. Genellikle mide korpus ve fundusda, 6. ve 7. dekatlarda, \%10-12 oranında, 2-3 milimetre çapında, sesil, multipl lezyonlar olarak saptanırlar (10). Bizim çalışmamızda 22 yaşında kadın ve 62 yaşında erkek olmak üzere 2 olguda her biri $6 \mathrm{~mm}$ olan 2 adet fundik gland polibi saptandi.

Adenomatöz polipler mide poliplerinin \%8-10'unu oluşturur. Genellikle kronik gastrit ve intestinal metaplazi gösteren mukozada gelişirler. Genellikle tek ve büyüktürler, sesil ya da saplı olabilirler. Histopatolojik özelliklerine göre tübüler, villöz, tübülovillöz olarak adlandırılırlar. Adenomatöz polip- lerin yaklaşık \%90'nını tübüler adenom, \%5-10'unu tübülovillöz ve \%1-2'sini de villöz tiptekiler oluşturur (4,5,8-10). Tübüler adenomlarda malignite gelişme riski daha azken, villöz ve tübülovillöz adenomlarda bu risk \%33 olarak bildirilmektadir (14). Bizim çalışmamızda GIS'de mide antrumda $\% 6,3$, mide korpusda $\% 4,8$ ve mide fundusda $\% 3$ oraninda polip izlendi. Midedeki poliplerin boyut ortalaması 8,2 milimetre (2-25 mm) saptandi. Literatürde hiperplastik ve fundik gland polipleri en sik görülen polipoid lezyonlar olarak bildirilirken gastrik polipler ve subtiplerinin sıklığı farklı çalışmalarda farklılık göstermekteydi $(4,7,8)$. Bizim çalışmamızda da 36 olguda $(\% 94,7)$ hiperplastik polip, 2 olguda $(\% 5,3)$ fundik gland polibi saptandi.

Kolorektal poliplerin çoğu adenomatöz poliplerdir. Tübüler adenomlar adenomatöz poliplerin \%80-86'sını, villöz adenomlar \%3-16'sını, tübülovillöz adenomlar \%8-16'sını oluştururlar $(2,15) .675$ olguluk bir seride tübüler adenom $\% 80,7$, tübülovillöz adenom $\% 16,4$ ve villöz adenom $\% 2,9$ olarak bulunurken (2), 2506 vakalık bir çalışmada \%75 tübüler adenom, \%15,3 tübülovillöz adenom ve \%11,7 villöz adenom (16), 428 olguluk bir çalışmada \%64,8 tübüler adenom, \%22,7 hiperplastik polip, \%3,7 jüvenil polip (25) ve 914 vakalık bir çalışmada da (26) \%68 tübüler adenom, \%7,2 tubulovillöz adenom, \%0,5 villöz adenom, \%4,3 hiperplastik polip, \%6 serrated adenom, \%0,8 adenokarsinom saptandığ bildirilmiştir. Bizim çalışmamızda tüm GIS polipleri içinde $\% 59,4$ tübüler adenom, \%23,2 hiperplastik polip, \%8,1 tübülovillöz adenom, \%6,3 inflamatuvar polip, \%1,1 yüzeyel kanserleşme gösteren tübülovillöz adenom, \%0,7 yüzeyel kanserleşme göteren adenomatöz polip, \%0,4 kanserleşme gösteren tübüler adenom saptandı ve görülme sıklıkları literatür ile uyumlu bulundu.

Adenomlarda yaş artıkça polip görülme sıklığı, büyüklüğü ve displazi gelişme oranı artmaktadır $(17,18)$. Literatürde erkeklerde \%53- 59, kadınlarda \%40-46, yaş ortalaması 43-61 arasında değişmektedir $(2,25,26)$. Çalışmamızda yaş ortalaması 61,7 yl olup, erkeklerde \%69,4, kadınlarda \%30,6 saptandı. Adenomlar $1 \mathrm{~cm}$ altında, $1-2 \mathrm{~cm}$ arasında ve $2 \mathrm{~cm}$ büyük olanlar olmak üzere büyüklük olarak üç grupta incelenir. Adenomların çoğu 1 cm'den küçüktür. Tübüler adenomlar $\% 77$ oraninda $<1 \mathrm{~cm}, \% 20$ oraninda $1-2 \mathrm{~cm}, \% 4$ oranında $>2$ cm'dir. Tübülovillöz adenomlar $\% 25$ oranında $<1 \mathrm{~cm}, \% 47$ oranında 1-2 cm, \%29 oranında $>2$ cm'dir. Villöz adenomlar $\% 14$ oraninda $<1 \mathrm{~cm}, \% 26$ oraninda $1-2 \mathrm{~cm}, \% 60$ oraninda $>2$ cm'dir. Büyük adenomlar distal kolon segmentlerinde daha sık görülür (17). Küçük polipler $5 \mathrm{~mm}$ ve daha küçük çaptaki poliplerdir. Hemen daima nonneoplastiktir. Villöz olan veya ağır displazi odağı içeren küçük poliplerin oranı $\% 1$ 'den azdır $(19,20)$. Çalışmamızda ortalama polip boyutu $8 \mathrm{~mm}(2-70 \mathrm{~mm})$ olarak saptandı. GIS'de polipler en fazla rektosigmoid bölgede oluşurlar ve çekuma doğru görülme 
sıklıkları azalır. Disanb ve arkadaşları (21) adenomların \%54 oranında splenik fleksura proksimalinde lokalize olduğunu bildirmişlerdir. Bech ve arkadaşları (22) adenomların en sık sigmoid kolonda yerleştiğini bildirmişlerdir. Liebermann ve arkadaşları (23) poliplerin \%44'ünün distal 60 cm'lik kısmında bulunduğunu bildirmişlerdir. 675 olguluk bir seride (2) \%47 sigmoid kolon, \%18,7 inen kolon, \%13,6 transvers kolon, \%12,5 rektumda, 428 olguluk bir çalışmada (25) \% 76,7 sol kolon, \%23,3 sağ kolonda, 914 vakalık bir çalışmada (26)

\section{KAYNAKLAR}

1. Itzkowitz SH, Potack J. Colonic polyps and polyposis syndromes. In: Sleisenger MH, Fordtran JS, (Eds). Sleisenger and Fordtran's Gastrointestinal and Liver Disease. 8 th ed. Philedeplhia. Saunders. 2006; 2713 36.

2. Konishi F, Morson BC. Pathology of colorectal adenomas: A colonoscopic survey. J Clin Pathol 1982; 35: 830-41.

3. Boland CR, Hzkowitz SH, Kim YS. Colonic polyps and gastrointestinal polyposis syndromes. Gastrointestinal disease, Sleisenger MH, Fordran JSS, Philadelphia, WB Saunders Company 1989; 2: 1483-518.

4. Oberhuber G, Stolte M. Gastric polyps: an update of their pathology and biological significance. Virchows Arch 2000; 437: 581-90.

5. Silverstein FE, Tytgat GNJ. Stomach II: Tumors and polyps, In: Silverstein FE, Tytgat GNJ, Editors. Gastrointestinal Endoscopy, 3rd ed. London. Mosby 1997; 147-80.

6. Jain R, Chetty R. Gastric hyperplastik polyps: a review. Dig Dis Sci 2009; 54: 1839-46.

7. Morais DJ, Yamanaka A, Zeiture JM, Andreollo NA. Gastric polyps: a retrospective analysis of 26.000 digestive endoscopies. Arq Gastroenterol 2007; 44: 14-7.

8. Archimandritis A, Spiliadis C, Tzivras M, et al. Gastric epithelial polyps: aretrospective endoscopic study of 12974 symptomatic patients. Ital J Gatroenterol 1996; 28: 387-90

9. Owen DA. The stomach, In: Sternberg SS, Editor. Diagnostic Surgical Pathology, 3rd ed. Philadelphia. Lippincott Williams \& Wilkins 1999; 1311-47.

10. Debongnie JC. Gastric polyps. Acta Gastroenterol Belg 1999; 62: 187-9.

11. Davaris P, Petraki K, Archimandritis A, et al. Mucosal hyperplastik polyps of the stomach. Do they have any potential to malignancy? Pathol Res Pract 1986; 181: 385-9.

12. Hizawa K, Fuchigami T, lida M, et al. Possible neoplastic transformation within gastric hyperplastic polyp. Application of endoscopic polypectomy. Surg Endosc 1995; 9: 714-8.
$\% 47$ rektosigmoid bölgede, \%19,3 inen kolon, \%11,2 transvers kolon, \%8,5 çıkan kolon, \%4,6 çekumda polip bildirilmiştir. Bizim çalışmamızda \%36,2 rektumda, \%16,6 transvers kolonda, \%13,3 inen kolonda, \%10,3 sigmoid kolonda, $\% 6,3$ mide antrumda, \%5,9 çekumda, \%4,8 mide korpusda, \%3,7 çıkan kolonda, \%3 mide fundusda polip saptandı. Üst ve alt gastrointestinal sisteme ait polipleri ayrı ayrı değerlendirdiğimiz çalışmamızda genel olarak tüm sonuçlarımızın literatür ile uyumluluk halinde olduğu görüldü.

13. Zea-Iriarte WL, Sekine I, Itsuno M, et al. Carcinoma in gastric hyperplastic polyps: a phenotypic study. Dig Dis Sci 1996; 41: 377-86.

14. Nakamura T, Nakano G. Histopathological classification and malignant change in gastric polyps. J Clin Pathol 1985; 38: 754-64.

15. O'Brien MJ, Winaver SJ, Zauber AG, et al. The National Polyp Study: Patient and polyp characteristics associated with high-grade dysplasia in colorectal adenomas. Gastroenterolgy 1990; 98: 371-9.

16. Muto T, Bussey HJR, Morson BC. The evolution of cancer of the colon and rectum. Cancer 1975: 36; 2251-70.

17. Williams AR, Balasoorriya BAW, Day DW. Polyp and cancer of the large bovel: A necropsy study in Liverpool. Gut 1982; 23: 835-42.

18. Vatn MH, Staisberg $\mathrm{H}$. The prevalence of polyps of the large intestine in Osio: An autopsy study. Cancer 1982; 49: 819-25.

19. Granqvist S, Cabrielsson N, Sundelin P. Diminutive colonic polypsclinical significance and managemant. Endoscopy 1979; 11: 36-42

20. Matek W, Guggenmoos-Holzmann I, Demling L. Follow-up of patients with colorectal adenomas. Endoscopy 1985; 17: 175-81.

21. DiSario JA, Fautch PG, Mai HD, et al. Prevalence and malignant potential of colorectal polyps in asymtomatic, avarage-risk men. Am J Gastroenterol 1991; 86: 941-5.

22. Bech K, Kronborg O, Fenger C. Adenomasand hyperplastic polyps in screening studies. World J Surg 1991; 15: 7-13.

23. Lieberman DA, Smith FW. Screening for colon malignancy with colonoscopy. Am J Gastroenterol 1991; 86: 946-51.

24. Joss JR. Nature and clinical significance of colorectal hyperlastic polyps. Semin Colon Rectal Surg 1991; 2: 246-52.

25. Altınparmak E, Sezgin O, Parlak E, Altıntaş E. Colorectal polyps 'The Yüksek Ihtisas experience'. Turk J Gastroenterol 2001; 12: 49-52.

26. Eminler AT, Sakallı M, Irak K, et al. Gastroenteroloji ünitemizdeki kolonoskopik polipektomi sonuçlarımız. Akademik Gastroenteroloji Dergisi 2011; 10: 112-5. 